\title{
A Cone Beam Computed Tomographic Analysis of Root Canal Preparations in Deciduous Teeth Using Self Adjusting Files- An In Vitro Study
}

\author{
Prabhakar AR, Renuka GN*, Saraswathi VN and \\ Chandrashekar MY \\ Department of Pedodontics and Preventive Dentistry, \\ Bapuji Dental College and Hospital, India \\ *Corresponding author: Renuka GN, Department \\ of Pedodontics and Preventive Dentistry, Bapuji Dental \\ College and Hospital, Davangere-577004, India
}

Received: March 20, 2017; Accepted: April 28, 2017; Published: May 18, 2017

\begin{abstract}
Background: The complex root canal anatomy of primary root canals is considered to be most challenging. Most of the root canal instruments available till date are ineffective in cleaning the root canal in three dimensions. Self Adjusting File (SAF) system was recently introduced. The aim of this study was to evaluate and compare remaining root thickness, centering ability, canal transportation and instrumentation time of Hand files and Self adjusting files in primary root canals using a Cone Beam Computed Tomographic (CBCT) analysis.
\end{abstract}

Study Design: This is an experimental, in vitro, intergroup study.

Material and Methods: Twenty eight extracted human primary teeth with minimum $7 \mathrm{~mm}$ root length were randomly divided into two groups (Group 1-Hand K-files, Group 2-SAF) were included in the study. CBCT images were taken before and after the instrumentation for each group. Remaining Dentin thickness, centering ability, canal transportation and instrumentation times were evaluated for each group.

Results: A significant difference was found in instrumentation time and canal transportation between Hand K-Files and SAF. Self adjusting files showed less canal transportation as compared to Hand K-Files and the mean instrumentation time of 'Self Adjusting Files' was significantly less than 'Hand K-Files'.

Conclusion: Self adjusting files system was found to be faster with much less errors in shaping the root canals of primary teeth and can hence be recommended for shaping the root canals of primary teeth.

Keywords: Self adjusting files; Cone beam computed tomography; Pulpectomy

\section{Introduction}

Biomechanical preparation of root canals is one of the main steps in achieving endodontic success due to enabling bacterial elimination, removal of debris and facilitating obturation. Endodontic mishaps such as Perforations, canal transportation, ledge and zip formation and separation of instruments are some of the complications encountered during root canal preparation of permanent teeth $[1,2]$. whereas in primary teeth, especially in primary molars due to fear of damage on the developing permanent tooth buds, as also due to difficulty in negotiating, cleaning, shaping, and filling the bizarre and tortuous canal anatomy of these teeth with resorbing and open apices. Many a time extraction of deciduous teeth having necrotic pulps with or without periapical infection is preferred following placement of the space maintainers. However, there is no better space maintainer than primary tooth itself, and the success rate of pulpectomy in primary teeth has been reported to be fairly high i.e., $80 \%$ to $100 \%$. So it becomes very important to save every primary molar [3].

Effective cleaning and shaping of root canal system is essential for achieving the biological and mechanical objectives of root canal treatment. Till date wide variety of instruments are available for the root canal instrumentation. But traditionally, the shaping of the root canals was achieved by the use of stainless steel hand files. However, over the last decades, technological advancements in rotary nickel-titanium instruments have led to new design concepts and easier, faster, and better root canal shaping [4]. These instruments performed better when the canals were straight, narrow and round, but were ineffective for cleaning long oval, flat and curved canals [5].

It has been reported that Niti rotary instruments may leave $40 \%$ to $60 \%$ of the root canal surface unchanged by the procedure. The rotary motion of these files tends to prepare the main root canal space into a circular shape, leaving unprepared buccal and lingual extensions [6].

This, yet unmet challenge resulted in a new branching point in the "evolution tree" of endodontics. One branch consists of attempts to meet this three-dimensional (3D) challenge by advanced irrigation methods [5]. The other new branch is represented by the SelfAdjusting File (SAF) system, which was recently introduced [5].

The self-adjusting files have shown to have better cleaning and shaping efficacy and better adaptation of the root canal filling than the traditional rotary files in permanent teeth [7-11]. In contrast to the permanent teeth, the primary teeth show more of flat root canals 

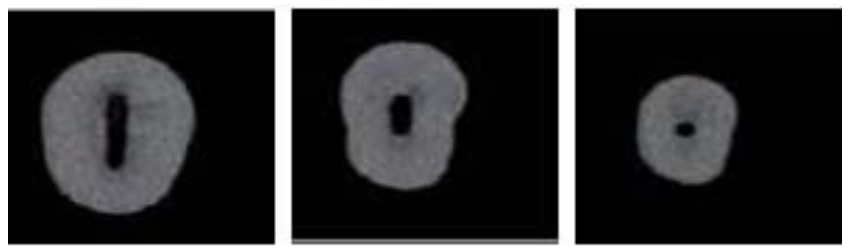

Figure 1: Sections taken at coronal, middle and apical level of the root.

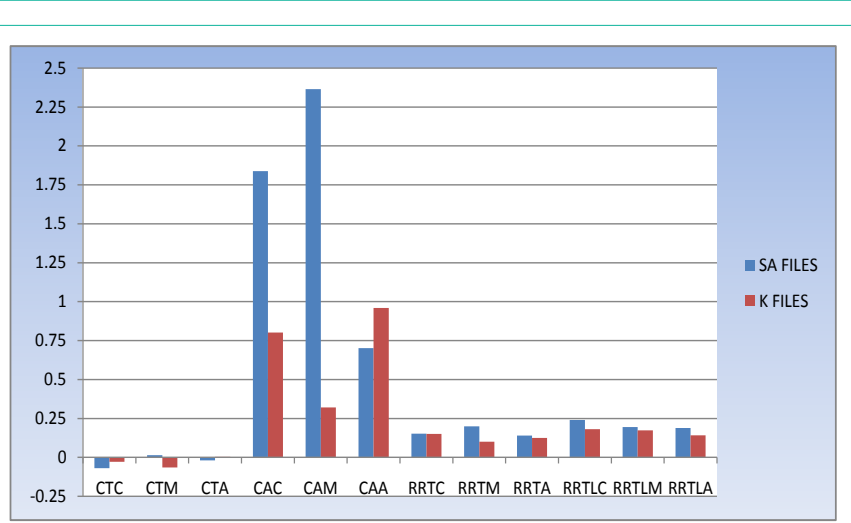

Graph 1: P-Value of $<0.001$ indicate significant difference in centering ability ratio measures at middle level of the canal.

and even more curved canals, and as these self-adjusting files like other rotary systems available till date do not impose any shape on the canals but rather they adapt to the canal architecture because of its and also self-adjusting files have never been used on primary teeth.

So we decided to conduct a study that aimed to evaluate whether the use of self-adjusting files in the primary root canals provides a better three dimensional cleaning and shaping.

\section{Materials and Methods}

Twenty eight freshly extracted human primary teeth (4 molars, 6 incisors, 4 canines) collected from the Department of Pedodontics and Preventive Dentistry, Bapuji Dental College and Hospital, Davangere, Karnataka, were included in the study. Institutional ethical board approval was obtained prior to the study. Groups that were used in the study:

Group 1: Hand K Files.

Group 2: Self adjusting files.

\section{Sample preparation}

The primary teeth with minimum two third root length were included and Teeth with resorbed roots were excluded from the study. The specimens were embedded in auto polymerizing acrylic resin using a plastic mold. In order to prevent the resin from entering and polymerizing into the apical foramen, the apices of the roots were sealed with wax. Acrylic resin was mixed according to the manufacturer's instructions and poured into the mold. Each sample was inserted into the unset acrylic resin so that its long axis was parallel to the long axis of the mold to ensure standardization of the specimens for the tomography images before and after root canal instrumentation [12].

\section{Root canal preparation}

Access cavity preparation was done using endo access bur to obtain straight line access, unroofing of the chamber was done and the pulp extripation was done for both the groups [13]. In Group 1 , the root canals were instrumented manually with K-files with the step-back technique up to file ISO size 30 [14], and in Group 2 initially a glide path was prepared to allow free insertion of a \#20 K-file to its working length, which allowed free insertion of the SAF to the full length of prepared canal [13].

\section{СВСТ}

Teeth were scanned (Dental digital imaging CBCT Centre, Davangere) before and after mechanical preparation with CBCT scanner with the following parameters: $60 \mathrm{kVp}, 12.5 \mathrm{~mA}$, field of view $8 \times 8$, and the sections were taken at coronal, middle and apical level of the root (Figure 1) [13]. The measurements of the canal before and after root canal preparation was done voxel by voxel wherein, M1 is the measurement of the quantity of voxels from the external surface of the mesial portion of the root to the mesial wall of the noninstrumented canal, M2 is the measurement of the quantity of voxels from the external root surface of the mesial portion of the root to the wall of the canal after instrumentation, D1 is the measurement of the quantity of voxels of the external surface of the distal portion of the root to the distal wall of the non-instrumented canal, D2 is the measurement of the quantity of voxels from the external surface of the distal portion of the root to the distal surface of the canal after instrumentation [13]. Canal transportation (CT) was calculated from the following equation [12].

\section{$(\mathrm{CT})=(\mathrm{M} 1-\mathrm{M} 2)-(\mathrm{D} 1-\mathrm{D} 2)$}

Regarding transportation direction, CT equal to 0 (zero) meant lack of transportation, Negative value represented transportation to the distal direction, Positive value represented transportation towards the mesial direction [13]. Centralization ability ratio was calculated using the values obtained during the measurement of transportation for both methods with the equation [12]. Centralization ability ratio $=(\mathrm{M} 1-\mathrm{M} 2) /(\mathrm{D} 1-\mathrm{D} 2)$. A result equal to 1.0 indicated perfect centralization. When this value was closer to zero, it was considered that the instrument had a lower capacity to maintain itself in the central axis of the canal [12]. Dentin thickness was measured on the axial cuts from the periphery of the pulp space to the outer surface of the tooth at three levels (cervical, middle, and apical) [12]. Instrumentation time was measured by digital chronometer during both the techniques [14].

\section{Results}

The data obtained was tabulated and subjected to appropriate statistical analysis; unpaired t- test was used for pair-wise comparison of canal transportation, centering ability and Dentin thickness between two groups. Mann Whitney $U$ test was used for the time comparison between two groups.The Statistical analysis was done using Statistical Package for Social Sciences (SPSS) version 16.

There was a significant difference in the centering ability and canal transportation measures at the middle level of the canal, SAF showed less canal transportation as compared to Hand files, and remained centered in the canal than hand files (P-value $<0.001$ Graph 1 and 
Table 1: SAF showed less canal transportation as compared to Hand files, and remained centered in the canal than hand files.

\begin{tabular}{|c|c|c|c|}
\hline & GROUP & MEAN $\pm S . D$ & P Value \\
\hline RDTCB & $\begin{array}{l}\text { HAND FILES } \\
\text { SAF }\end{array}$ & $\begin{array}{l}0.15 \pm 0.16 \\
0.17 \pm 0.11\end{array}$ & 0.721 \\
\hline RDTMB & $\begin{array}{l}\text { HAND FILES } \\
\text { SAF }\end{array}$ & $\begin{array}{l}0.10 \pm 0.15 \\
0.14 \pm 0.11\end{array}$ & 0.410 \\
\hline RDTAB & $\begin{array}{c}\text { HAND FILES } \\
\text { SAF }\end{array}$ & $\begin{array}{l}0.12 \pm 0.14 \\
0.18 \pm 0.22\end{array}$ & 0.374 \\
\hline RDTCL & $\begin{array}{c}\text { HAND FILES } \\
\text { SAF }\end{array}$ & $\begin{array}{l}0.18 \pm 0.13 \\
0.14 \pm 0.08\end{array}$ & 0.356 \\
\hline RDTML & $\begin{array}{l}\text { HAND FILES } \\
\text { SAF }\end{array}$ & $\begin{array}{l}0.17 \pm 0.17 \\
0.15 \pm 0.08\end{array}$ & 0.661 \\
\hline RDTAL & $\begin{array}{c}\text { HAND FILES } \\
\text { SAF }\end{array}$ & $\begin{array}{l}0.14 \pm 0.06 \\
0.12 \pm 0.12\end{array}$ & 0.618 \\
\hline CTC & $\begin{array}{c}\text { HAND FILES } \\
\text { SAF }\end{array}$ & $\begin{array}{l}-0.02 \pm 0.19 \\
0.03 \pm 0.04\end{array}$ & 0.273 \\
\hline CTM & $\begin{array}{c}\text { HAND FILES } \\
\text { SAF }\end{array}$ & $\begin{array}{l}-0.06 \pm 0.24 \\
0.001 \pm 0.09\end{array}$ & 0.353 \\
\hline CTA & $\begin{array}{c}\text { HAND FILES } \\
\text { SAF }\end{array}$ & $\begin{array}{c}0.003 \pm 0.14 \\
0.07 \pm 0.07\end{array}$ & 0.288 \\
\hline CAC & $\begin{array}{l}\text { HAND FILES } \\
\text { SAF }\end{array}$ & $\begin{array}{c}0.80 \pm 0.941 \\
1.2 \pm 0.32\end{array}$ & 0.088 \\
\hline CAM & $\begin{array}{c}\text { HAND FILES } \\
\text { SAF }\end{array}$ & $\begin{array}{l}0.32 \pm 0.55 \\
1.04 \pm 0.49\end{array}$ & 0.001 \\
\hline CAA & $\begin{array}{l}\text { HAND FILES } \\
\text { SAF }\end{array}$ & $\begin{array}{c}0.95 \pm 0.86 \\
1.1 \pm 0.56\end{array}$ & 0.529 \\
\hline
\end{tabular}

Table 2: Regarding dentin thickness and centering ability ratio.

\begin{tabular}{|c|c|}
\hline Abbreviation & Full Form \\
\hline RDTCB & Remaining Dentin thickness-cervical 1/3rd-buccal aspect \\
\hline RDTMB & Remaining Dentin thickness-middle $1 / 3$ rd-buccal aspect \\
\hline RDTAB & Remaining Dentin thickness-apical 1/3rd-buccal aspect \\
\hline RDTCL & Remaining Dentin thickness-cervical $1 / 3$ rd-lingual aspect \\
\hline RDTML & Remaining Dentin thickness-middle $1 / 3$ rd-lingual aspect \\
\hline RDTAL & Remaining Dentin thickness-apical $1 / 3$ rd- lingual aspect \\
\hline СТС & Canal transportation-cervical $1 / 3$ rd \\
\hline СТМ & Canal transportation-middle $1 / 3$ rd \\
\hline CTA & Canal transportation-apical $1 / 3 r d$ \\
\hline CAC & Centering ability- cervical $1 / 3 r d$ \\
\hline CAM & Centering ability- middle $1 / 3$ rd \\
\hline CAA & Centering ability- apical $1 / 3 r d$ \\
\hline
\end{tabular}

Table 1). A highly significant difference in the instrumentation time of SAF and Hand files was found. The mean instrumentation time of Hand files was 4.92 minutes compared to that of SAF which was 3 minutes. (P-value $<0.001$ Graph 2 and Table 1). Regarding Dentin thickness and centering ability ratio, Statistical analysis showed no significant difference between SAF and hand files at any level (Graph 1 and Table 2).

\section{Discussion}

The complex root canal anatomy of primary root canals is considered to be most challenging. Most of the root canal instruments available till date are ineffective in shaping the root canal in three dimensions, \& most often leave buccal and lingual extensions unprepared and this phenomenon cannot be seen in routine radiographic techniques we use as it is a 2 Dimensional image. So the present study was conducted that aimed to evaluate whether the use of self-adjusting files in the primary root canals provides a better three dimensional cleaning and shaping along with 3 Dimensional images

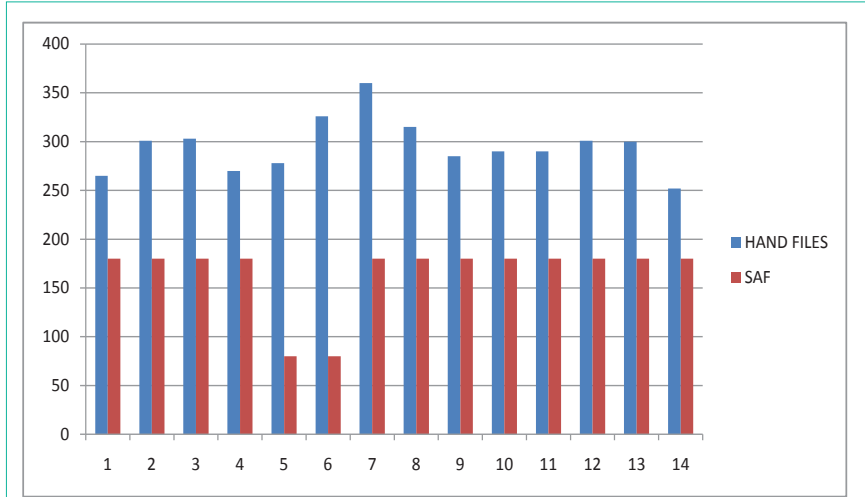

Graph 2: $P$ value $<0.001$ which shows $S A F$ is better than Hand file group.
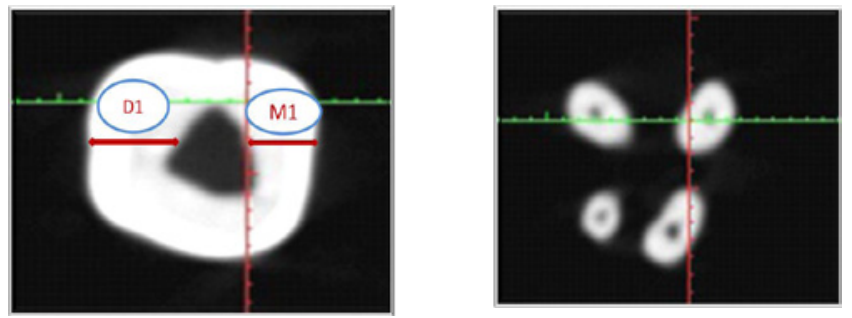

Figure 2: Measurement of the canal before root canal preparation.
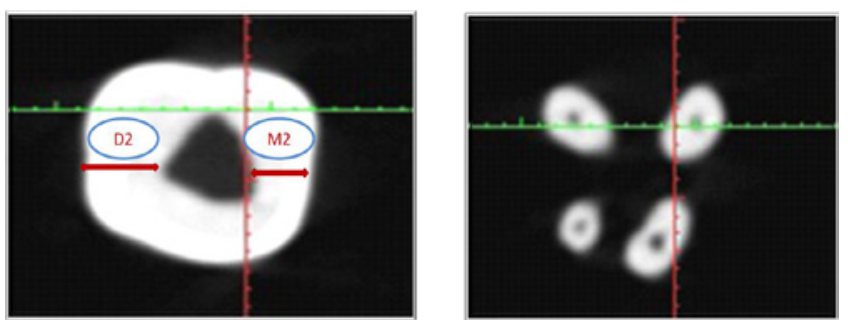

Figure 3: Measurement of the canal after root canal preparation.

taken with the help of Cone beam computed tomographic technique.

The SAF has a unique file design, which has a hollow file design, that which is elastically compressible so that it adapts itself to the cross section of the canal in all three dimensions and also the irrigant is delivered continuously through the hollow file which was provided by a VATEA peristaltic pump (ReDent-Nova) at a rate of $4 \mathrm{~mL} / \mathrm{min}$, which is an added advantage in treating children as we know that children have very less attention span [6].

The SAF system is unique in its operation than other rotary files available till date, the SAF file is used with in and out pecking motion that vibrates at $5000 \mathrm{rpm}$, which causes sonic activation of the irrigant throughout the procedure. And also the nickel titanium lattice of SAF is easily compressible in oval shaped canals, i.e., if the lattice cylinder of the file which has a $1.5 \mathrm{~mm}$, it spreads buccolingually up to $2.4 \mathrm{~mm}$. This shows that how well it adapts to the buccal and lingual recesses which were earlier uneffected by the rotary files [6]. The outer surface of the file has abrasive surface which abrades the dentin creating dentinal dust which is removed by the irrigant which is continuously delivered, rather than cutting like other files which create dentinal chips that results in clogging of canals. As we know that Endodontic 
mishaps are inevitable even with experienced operators. With this new innovation of $3 \mathrm{D}$ shaping most of the procedural errors can be eliminated.

In the present study, Teeth with Minimum $7 \mathrm{~mm}$ of root length were selected where at least two third of root length was the inclusion criteria. Till date number of methods have been used to evaluate canal shape before and after instrumentation, out of which intraoral periapical radiograph are routinely used but these radiographic techniques provide two dimensional images which represent only bucco-lingual projection. Cone Beam Computed Tomographic imaging was employed for this study as it provides detailed three dimensional observations as evidenced by previous studies. The CBCT provides images in orthogonal planes as well as in oblique planes, which is an added advantage for measuring Dentin thickness, apical canal transportation and canal centering ability.

The results obtained in our study showed less canal transportation for the SAF system as compared to the Hand K-File system.

The less instrumentation time in SAF system can be explained by the fact that SAF hollow design allows the irrigant to be delivered continuously so that time used for irrgation of canals is saved.

The SAF file is for single use as the endodontic instruments has been recommended recently, to decrease chances of instrument separation due to fatigue and also the most unique feature of SAF is that its lattice gets detached but It does not get completely separated so that it is more safer for use in pediatric patients, as the patients become more uncooperative in broken instrument retrieval as they have short attention span. And more importantly single use of file eliminate possible cross contamination. Because of the inability to completely clean and sterilize endodontic instruments.

\section{Conclusion}

Within the limitations of this study, the SAF has proved to be a faster better and safer system with less procedural errors as compared to Hand K-Files. This study represents a new step in pediatric endodontic file development which may overcome many of the shortcomings of the current file systems.

\section{References}

1. Yoldas O, Yilmaz S, Atakan G, Kuden C, Kasan Z. Dentinal microcrack formation during root canal preparations by different NiTi rotary instruments and the self-adjusting file. J Endod. 2012; 38: 232-235.
2. Jafarzadeh $\mathrm{H}$, Abbott $\mathrm{PV}$. Ledge formation: review of a great challenge in endodontics. J Endod. 2007; 33: 1155-1162.

3. Ahmed HM. Pulpectomy procedures in primary molar teeth. Eur J Gen Dent. 2014; 3: 3-10.

4. Capar ID, Altunsoy M, Arslan H, Ertas H, Aydinbelge HA. Fracture strength of roots instrumented with self-adjusting file and the ProTaper rotary systems. J Endod. 2014; 40: 551-554.

5. Solomonov M. Eight months of clinical experience with the Self-Adjusting File system. J Endod. 2011; 37: 881-887.

6. De-Deus G, Souza EM, Barino B, Maia J, Zamolyi RQ, Reis C, et al. The self-adjusting file optimizes debridement quality in oval-shaped root canals. J Endod. 2011; 37: 701-705.

7. Metzger Z, Zary R, Cohen R, Teperovich E, Paqué F. The quality of root canal preparation and root canal obturation in canals treated with rotary versus selfadjusting files: a three-dimensional micro-computed tomographic study. J Endod. 2010; 36: 1569-1573.

8. Dietrich MA, Kirkpatrick TC, Yaccino JM. In vitro canal and isthmus debris removal of the self-adjusting file, $\mathrm{K} 3$, and WaveOne files in the mesial root of human mandibular molars. J Endod. 2012; 38: 1140-1144.

9. Solomonov M, Paque F, Kaya S, AdigÃuzel O, Kfir A, YiÄ̈̈it-Ã-zer S. Selfadjusting files in retreatment: a high-resolution micro-computed tomography study. J Endod. 2012; 38: 1283-1287.

10. De-Deus G, Barino B, Marins J, Magalhães K, Thuanne E, Kfir A. Selfadjusting file cleaning-shaping-irrigation system optimizes the filling of ovalshaped canals with thermoplasticized gutta-percha. J Endod. 2012; 38: 846849 .

11. Metzger Z, Teperovich E, Zary R, Cohen R, Hof R. The self-adjusting file (SAF). Part 1: respecting the root canal anatomy--a new concept of endodontic files and its implementation. J Endod. 2010; 36: 679-690.

12. Elsherief SM, Zayet MK, Hamouda IM. Cone-beam computed tomography analysis of curved root canals after mechanical preparation with three nickeltitanium rotary instruments. J Biomed Res. 2013; 27: 326-335.

13. Azar MR, Safi L, Nikaein A. Comparison of the cleaning capacity of Mtwo and Pro Taper rotary systems and manual instruments in primary teeth. Dent Res J (Isfahan). 2012; 9: 146-151.

14. Madan N, Rathnam A, Shigli AL, Indushekar KR. K-file vs. ProFiles in cleaning capacity and instrumentation time in primary molar root canals: an in vitro study. J Indian Soc Pedod Prev Dent. 2011; 29: 2-6.
Austin J Dent - Volume 4 Issue 4 - 2017

ISSN : 2381-9189 | www.austinpublishinggroup.com

Renuka et al. (@) All rights are reserved
Citation: Prabhakar AR, Renuka GN, Saraswathi VN and Chandrashekar MY. A Cone Beam Computed Tomographic Analysis of Root Canal Preparations in Deciduous Teeth Using Self Adjusting Files- An In Vitro Study. Austin J Dent. 2017; 4(4): 1078. 